\title{
IDENTIFIKASI ALAT TANGKAP IKAN RAMAH LINGKUNGAN YANG BEROPERASI DI PERAIRAN SUNGAI ALAI KABUPATEN TEBO PROVINSI JAMBI
}

\author{
Yusuf Rohadi $^{1}$ Rini Hertati ${ }^{2 *}$ Muhammad Natsir Kholis $^{2}$

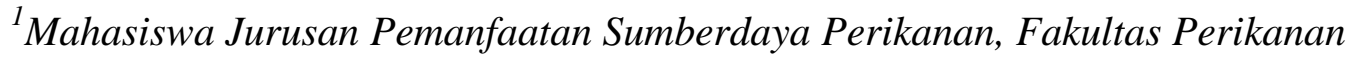 \\ Universitas Muara Bungo \\ ${ }^{2}$ Staf Pengajar Jurusan Pemanfaatan Sumberdaya Perikanan \\ Fakultas Perikanan Universitas Muara Bungo \\ *Email : rinihertati4@gmail.com
}

\begin{abstract}
ABSTRAK
Penelitian ini dilaksanakan pada bulan Maret-April 2020. Lokasi penelitian di perairan sungai alai Kabupaten Tebo Provinsi Jambi. Tujuan penelitian ini adalah untuk mengidentifikasi alat tangkap ikan yang beroperasi di sungai alai dan mengetahui tingkat keramah lingkungannya. Adapun pengambilan sampel menggunakan metode purposive sampling, artinya pengambilan sampel penelitian diambil sesuai kebutuhan penelitian. Dari hasil identifikasi alat penangkapan ikan diperoleh 4 kelompok jenis alat penangkapan ikan yaitu terdiri dari: kelompok jenis alat tangkap perangkap (sruwo, ambat, bubu kawat), kelompok jenis alat tangkap jaring insang (jaring), kelompok jenis alat tangkap pancing (pancing lempar, pancing tajur, rawai), kelompok jenis alat tangkap penjepit dan melukai (tembak ikan). Dari 8 jenis alat penangkapan yang teridentifikasi, semuanya berkategori sangat ramah lingkungan.
\end{abstract}

Kata Kunci : Alat Penangkapan Ikan, Identifikasi, Ramah Lingkungan, Sungai Alai, Jambi

\begin{abstract}
This research was conducted in March-April 2020. The research location was in the waters of the Alai river, Tebo Regency, Jambi Province. The purpose of this study was to identify fishing gear that operates in the Alai river and determine the level of environmental friendliness. The sampling method was purposive sampling, meaning that the research sample was taken according to the research needs. From the results of the identification of fishing gears, there are 4 groups of fishing gear types, namely: groups of types of traps (sruwo, ambat, wire traps), groups of gill nets (nets), groups of types of hook and lines (throwing rods, tajur fishing line, longline), a group of types of fishing gear clasping and injuring (shooting fish). Of the 8 types of fishing gear identified, all were categorized as very environmentally friendly.
\end{abstract}

Keywords: Fishing Gear, Identification, Environmentally Friendly, River Alai, Jambi 


\section{PENDAHULUAN}

\section{Latar Belakang}

Pengelolaan sumberdaya ikan sangat erat kaitannya dengan pengelolaan operasi penangkapan ikan dan sasaran penangkapan ikan yang dilakukan. Kegiatan ini berusaha untuk menjaga kelestarian sumberdaya ikan dari ancaman kepunahan dan telah dilakukan sejak lama oleh berbagai ahli penangkapan ikan di seluruh dunia (Dahuri, 2000; Sumardi et al., 2014).

Kriteria teknologi penangkapan ikan memiliki beberapa aturan penting, yaitu: selektifitas yang tinggi, tidak membahayakan nelayan, tidak destruktif terhadap nelayan, produksinya berkualitas, produknya tidak tidak membahayakan konsumen, ikan buangan minimum, tidak menangkap spesies yang dilindungi atau terancam punah, dampak minimum terhadap keanekaragaman hayati dan dapat diterima secara sosial.

Merujuk kepada pernyataan ini dapat disimpulkan bahwa operasi penangkapan ikan dapat dikatakan berjalan lancar apabila suatu usaha perikanan memiliki beberapa criteria teknologi penangkapan ikan yang ramah lingkungan (Monintja, 2001; Sumardi et al., 2014).

Kabupaten Tebo memiliki potensi sumberdaya perairan yang merupakan salah satu sumber pendapatan bagi masyarakat baik itu perikanan budidaya maupun perikanan tangkap. Potensi perikanan di Kabupaten Tebo sebesar 1.271 ton terbagi atas perairan

\section{METODE PENELITIAN Waktu dan Tempat Penelitian}

Penelitian ini dilaksanakan pada bulan Maret - April 2020. Lokasi penelitian di perairan sungai alai yang umum sebesar 312 ton dan budidaya sebesar 959 ton. Sumber perairan di Kabupaten Tebo yang memiliki potensi perikanan tangkap meliputi sungai batang sumay, sungai batang tabir, sungai batang tebo, sungai batang langsisip, sungai batang jujuhan, sungai alai, rawa-rawa, danau tanduk dan danau sigombak (BPS Provinsi Jambi, 2018).

Sungai alai merupakan cabang anak sungai dari sungai batanghari yang berhulu di perbatasan Provinsi Sumatera Barat membelah Kecamatan Rimbo Ulu, Kecamatan Rimbo Bujang, Kecamatan Rimbo Ilir dan berhilir di Kecamatan Tebo Tengah. Di perairan sungai alai terdapat berbagai aktivitas penangkapan ikan yang dilakukan oleh masyarakat nelayan. Dengan adanya aktivitas penangkapan tersebut, sampai saat ini belum ada penelitian yang menjelaskan bagaimana bentuk konstruksi alat tangkap yang beroperasi di perairan sungai alai, apakah alat tangkap yang digunakan oleh masyarakat nelayan di perairan sungai alai sudah berkategori/berkriteria alat tangkap yang ramah lingkungan. Berdasarkan hal tersebut, maka perlu dilakukan penelitian tentang "Identifikasi Alat Tangkap Ramah Lingkungan yang Beroperasi di Perairan Sungai Alai Kabupaten Tebo Provinsi Jambi". Tujuan penelitian ini yaitu mengidentifikasi alat tangkap yang beroperasi di perairan sungai alai dan menilai tingkat keramah lingkungannya

melewati 4 Kecamatan yaitu Kecamatan Rimbo Ulu, Bujang, Ilir dan Tebo Tengah, Kabupaten Tebo, Provinsi Jambi (Gambar 1). 


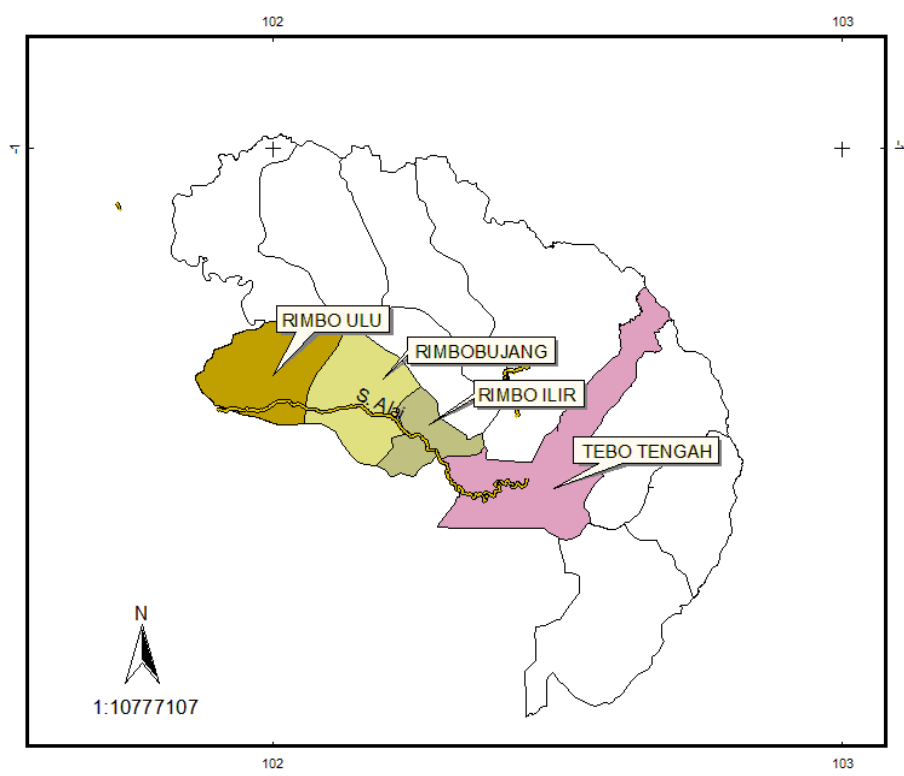

(2020

Gambar 1. Peta Lokasi Penelitian

\section{Metode Penelitian}

Metode penlitian yang digunakan pada penelitian ini yaitu metode survei. Adapun pengambilan sampel menggunakan teknik purposive sampling artinya pengambilan sampel penelitian diambil sesuai kebutuhan penelitian. Menurut Sugiyono (2014); Lisna et al., (2018), teknik purposive sampling adalah teknik pengambilan sampel sumber data dengan pertimbangan tertentu. Adapun pertimbangannya yaitu: melakukan survei kepada masyarakat nelayan sebagai responden dan alat tangkap sebagai objek penelitian, kemudian melakukan pengukuran terhadap 2 sampel dari tiap populasi alat tangkap dan dianggap bisa mewakili keseluruhan alat tangkap yang digunakan pada lokasi penelitian.

\section{Sumber Data Penelitian}

Data primer: diperoleh dari teknik wawancara dengan masyarakat nelayan melalui kuisioner. Observasi lapangan untuk mengidentifikasi jenis alat tangkap yang digunakan oleh masyarakat nelayan perairan sungai alai di 4 Kecamatan yang menjadi lokasi penelitian.

Data sekunder: pengumpulan informasi dari stakeholder, instansi dan studi literatur yang berkaitan dengan topik penelitian.

\section{Alat dan Bahan \\ Adapun alat yang digunakan dalam penelitian ini adalah alat tulis, penggaris, meteran dan kamera digital. Bahan yang digunakan dalam penelitian ini adalah kuisioner dan alat tangkap yang digunakan oleh masyarakat nelayan.}

\section{Analisis Data}

Analisis data yang digunakan dalam penelitian ini yaitu analisis deskriptif. Menurut Nawawi (1998), analisis deskriptif yaitu prosedur pemecahan masalah yang di selidiki dengan menggambarkan/melukiskan keadaan subyek/obyek penelitian pada saat sekarang berdasarkan fakta - fakta yang tampak atau sebagaimana adanya. 
1. Analisis Identifikasi

Penangkapan Ikan

Analisis dilakukan dengan cara mengukur dan mengamati konstruksi alat penangkapan ikan yang ditemukan saat penelitian. Kemudian data yang sudah diperoleh dianalisa dan dicocokan mengacu pada PERMEN KP No.71/2016 dan Internasional Standard Stastictical Classification of Fishing Gear (ISSCFG) kemudian ditabulasikan dalam bentuk tabel dan digambarkan. Saat menganalisis dibantu Software Ms. Word 2010 dan Ms. Excell 2010.

2. Analisis Alat Penangkapan Ikan Ramah Lingkungan

Tingkat keramahan lingkungan alat tangkap yang beroperasi di perairan sungai alai dilihat dengan menggunakan 9 (sembilan) kriteria teknologi penangkapan ramah lingkungan berdasarkan ketentuan FAO (1995), yaitu : 1) Alat tangkap harus memiliki selektivitas yang tinggi; 2) Alat tangkap tidak merusak habitat dan tempat berkembangbiak ikan; 3) Tidak membahayakan nelayan; 4) Menghasilkan ikan yang bermutu; 5) Produksi tidak membahayakan kesehatan konsumen; 6) Hasil tangkapan yang terbuang minimum.7) Alat tangkap harus memberikan dampak minimum terhadap biodiversity; 8) Tidak menangkap jenis ikan yang dilindungi undang-undang

\section{HASIL DAN PEMBAHASAN Identifikasi Alat Penangkapan Ikan}

Setiap jenis alat penangkapan ikan umumnya mempunyai spesifikasi dan ciri khas tersendiri, hal ini menunjukan bahwa satu alat tangkap tertentu ditujukan untuk menangkap spesies tertentu pula dan disesuaikan dengan desain ukuran alat tangkap yang akan digunakan (Dirjen Perikanan atau terancam punah; dan 9) Dapat diterima secara sosial.

Pada setiap masing - masing kriteria nantinya terdapat 4 sub kriteria yang akan di nilai. Dari 4 sub-kriteria tersebut pembobotan nilainya di tinjau dari nilai terendah hingga nilai tertinggi. Cara pembobotan dari 4 subkriteria tersebut adalah dengan membuat skor dari nilai terendah hingga nilai tertinggi seperti berikut: skor 1 untuk sub-kriteria pertama, skor 2 untuk sub-kriteria kedua, skor 3 untuk sub-kriteria ketiga, skor 4 untuk sub-kriteria keempat. Indeks bobot nilai dapat ditetapkan sebagai berikut:

1. $(10-17)=$ Sangat Tidak Ramah Lingkungan.

2. $(18-26)=$ Tidak Ramah Lingkungan.

3. $(27-35)=$ Ramah Lingkungan.

4. $(36-40)=$ Sangat Ramah Lingkungan.

Sehingga untuk menentukan hasil akhirnya yaitu dengan nilai total skor dibagi jumlah responden atau digunakan rumus ketetapan sebagai berikut (Sima et al., 2014; Kurrohman et al., 2008).

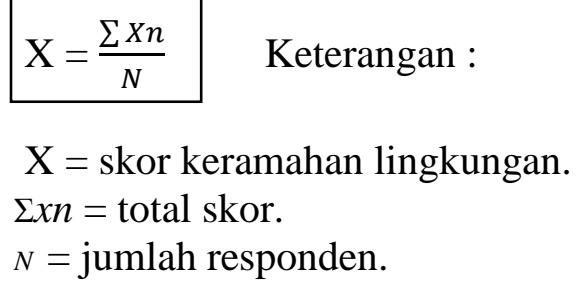

Tangkap, 2005). Berdasarkan hasil penelitian di perairan sungai alai Kabupaten Tebo, alat tangkap yang ditemukan dan teridentifikasi yaitu berjumlah 286 unit. Pada penelitian yang ini ditemukan berbagai jenis alat penangkapan ikan, maka dari itu perlu adanya pengklasifikasian alat penangkapan ikan untuk lebih memudahkan dalam melihat dan 
membedakan jenis alat penangkapan ikan. Dalam pengklasifikasian alat penangkapan ikan mengacu pada PERMEN KP No: 71/2016 dan
ISSCFG. Lebih jelas dapat di lihat pada Tabel 1.

Tabel 1. Klasifikasi Jenis Alat Penangkapan Ikan yang Teridentifikasi di Perairan Sungai Alai Kabupaten Tebo

\begin{tabular}{|c|c|c|c|c|}
\hline \multirow{2}{*}{ No. } & \multirow{2}{*}{$\begin{array}{c}\text { Nama Lokal Alat } \\
\text { Tangkap }\end{array}$} & \multicolumn{2}{|c|}{$\begin{array}{l}\text { Klasifikasi Jenis Alat } \\
\text { Penangkapan Ikan }\end{array}$} & \multirow{2}{*}{$\begin{array}{c}\text { Jumlah } \\
\text { Teridentifikas } \\
\text { ( Unit ) }\end{array}$} \\
\hline & & $\begin{array}{c}\text { PERMEN KP } \\
\text { No:71/2016 }\end{array}$ & ISSCFG & \\
\hline 1. & Sruwo (bubu galon) & Perangkap & Traps & 40 \\
\hline 2. & Jaring & Jaring insang & Gillnets & 20 \\
\hline 3. & Pancing lempar & Pancing & Hook and lines & 12 \\
\hline 4. & Ambat & Perangkap & Traps & 1 \\
\hline 5. & Tembak ikan & $\begin{array}{l}\text { Penjepit dan } \\
\text { melukai }\end{array}$ & $\begin{array}{l}\text { Grappling and } \\
\text { wounding }\end{array}$ & 1 \\
\hline 6. & Pancing tajur & Pancing & Hook and lines & 200 \\
\hline 7. & Rawai & Pancing & Hook and lines & 3 \\
\hline 8. & Bubu kawat & Perangkap & Traps & 9 \\
\hline \multicolumn{4}{|c|}{ Total } & 286 \\
\hline
\end{tabular}

Berdasarkan (Tabel 1) pengklasifikasian alat penangkapan ikan yang teridentifikasi di perairan sungai alai berdasarkan PERMEN KP No:71/2016 dan ISSCFG diperoleh 4 kelompok jenis alat penangkapan ikan yaitu terdiri dari: kelompok jenis alat tangkap perangkap (sruwo, ambat, bubu kawat), kelompok jenis alat tangkap jaring insang (jaring), kelompok jenis alat tangkap pancing (pancing lempar, pancing tajur, rawai), kelompok jenis alat tangkap penjepit dan melukai (tembak ikan).

\section{Alat Tangkap Sruwo (Bubu Galon)}

Sruwo adalah alat tangkap sejenis perangkap mempunyai cara kerja seperti bubu, namun bahan dan teknik pembuatannya tidak sama seperti pembuatan bubu pada umumnya. Biasanya alat tangkap ini terbuat dari galon sebagai bahan utamanya. Masyarakat nelayan memanfaatkan galon bekas tempat minyak sayur berukuran 5 liter. Selain mudah didapatkan alasan lain menggunakan galon yaitu cara pembuatannya relatif lebih mudah dan tidak membutuhkan waktu lama. Konstruksi sruwo terdiri dari mulut sruwo, injab, badan, pintu pengeluaran dan tapan (bambu). Ukuran tapan memiliki panjang $20 \mathrm{~cm}$ dan berdiameter $7 \mathrm{~cm}$, injab berukuran diameter $70 \mathrm{~mm}$, bagian badan memiliki lebar $18 \mathrm{~cm}$ dan tinggi $30 \mathrm{~cm}$, pintu pengeluaran berdiameter $90 \mathrm{~mm}$. Konstruksi alat tangkap sruwo dapat dilihat pada (Gambar 2).

Alat tangkap ini hanya digunakan untuk menangkap ikan-ikan kecil, tetapi tidak menutup kemungkinan apabila ukuran tapan yang digunakan diameternya berukuran besar maka ikan-ikan besar pun bisa ikut terperangkap dengan catatan apabila ukuran diameter tapan besar maka konsekuesinya umpan yang dibutuhkan akan lebih banyak. Untuk bagian pengikat menggunakan karet ban, 
bagian pengikat ini tidak mutlak menggunakan karet, bisa saja menggunakan kawat atau tali. Pada umumnya injab yang digunakan pada bubu terbuat dari bambu namun injab yang digunakan untuk sruwo terbuat dari gelas bekas minuman berukuran $190 \mathrm{ml}$. Ukuran lubang tempat pemasangan injab menyesuaikan dengan diameter injab yang digunakan.

Pengoperasiannya dipasang

menggunakan bantuan tiang/pancang sebagai penyangga dalam air supaya tidak terbalik. Lokasi pemasangan yaitu dibagian pinggir sungai dengan kondisi perairan yang tenang ataupun sedikit berarus. Umpan yang digunakan yakni menggunakan buah kelapa sawit yang sudah ditumbuk kemudian dicampur pur ayam. Umpan ini nantinya dimasukan ke dalam tapan. Untuk melihat hasil tangkapan, sruwo dipasang kurang lebih 24 jam. Sebagai contoh, apabila nelayan memasang sruwo pada hari senin pukul 13.00 WIB, maka pengambilan dilakukan pada hari selasa pukul 13.00 WIB. Pada saat pengambilan hasil tangkapan juga dilakukan pengecekan umpan, apabila umpan sudah habis maka harus di isi ulang untuk dipasang kembali.

Hasil tangkapan menggunakan alat tangkap sruwo ini yaitu ikan betok, boleng/bendera, lampam, mata merah, seluang, bandengan/wader, keting/senggiring.

$\begin{array}{ll}\text { Nama Lokal } & \text { : Sruwo (Bubu Galon) } \\ \text { Nama Nasional } & \text { : Perangkap } \\ \text { Nama International } & : \text { Traps } \\ \text { Jumlah Alat } & : \text { 40 unit } \\ \text { Daerah Operasi } & \text { : perairan sungai alai }\end{array}$

Tabel 2. Identifikasi Konstruksi Alat Tangkap Sruwo (Bubu Galon)

\begin{tabular}{llccccc}
\hline No & Komponen & $\begin{array}{l}\text { Panjang } \\
(\mathrm{cm})\end{array}$ & $\begin{array}{l}\text { Lebar } \\
(\mathrm{cm})\end{array}$ & $\begin{array}{l}\text { Tinggi } \\
(\mathrm{cm})\end{array}$ & $\begin{array}{l}\text { Mesh size } \\
(\mathrm{mm})\end{array}$ & $\begin{array}{l}\text { Diameter/Ø } \\
(\mathrm{mm})\end{array}$ \\
\hline 1. & Mulut Sruwo & - & - & - & - & 65 \\
2 & Injab & - & - & 10 & - & 70 \\
3. & $\begin{array}{l}\text { Badan } \\
\text { 4. }\end{array}$ & - & 18 & 30 & - & - \\
& $\begin{array}{l}\text { Pintu } \\
\text { Pengeluaran }\end{array}$ & - & - & - & - & 90 \\
5. $\begin{array}{l}\text { Tutup bubu }) \\
\text { Tapan/bambu }\end{array}$ & 20 & - & - & - & 70 \\
6. & Karet ban bekas & 30 & - & - & - & -
\end{tabular}

Sumber : Data Penelitian 2020. 


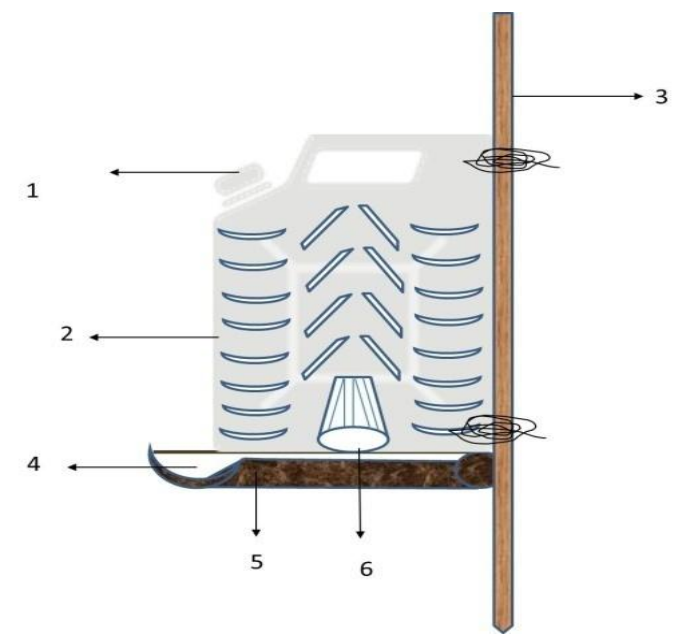

Keterangan:

1. Pintu pengeluaran

2. Badan

3. Kayu pancang

4. Pintu tapan

5. Tapan

6. Injab

Gambar 2. Konstruksi Alat Tangkap Sruwo

2. Alat Tangkap Jaring

Alat tangkap jaring yang digunakan oleh masyarakat nelayan memiliki cara kerja yang sama dengan jenis alat tangkap jaring insang pada umumnya, yaitu menghadang arah ruaya ikan. Jika dilihat dari konstruksinya sangat sederhana dan biaya pembuatannya cukup terjangkau oleh masyarakat nelayan. Jaring yang dikategorikan jaring insang dasar (bottom gillnet) ini memiliki konstruksi terdiri dari tali ris, webbing (badan jaring) dan pemberat. Ukuran panjang tali ris yaitu $20 \mathrm{~m}$, mesh size $1 / 2$ inci $(1,27 \mathrm{~cm})$, dan pemberat berjumlah 13 unit berbahan genteng dengan berat sekitar 70 - 80 g. Konstruksi alat tangkap jaring dapat dilihat pada (Gambar 3).

Jika dilihat sekilas alat tangkap jaring ini tidak menggunakan pelampung dibagian atasnya. Dengan alasan sungai yang menjadi tempat pemasangan tidak terlalu lebar maka dari itu saat pengoperasian cukup dengan mengikat kuat tali ris pada pohon atau kayu pancang yang sudah ditentukan. Alasan lain yaitu sungai yang menjadi tempat pemasangan hanya memiliki kedalaman sekitar 90 $100 \mathrm{~cm}$ atau batas leher orang dewasa.

Menurut Martasuganda (2002); Irpan et al., (2018); Kholis et al., (2018) jaring insang atau gill net adalah satu jenis alat tangkap ikan dari bahan jaring yang bentuknya empat persegi panjang dengan ukuran mata jaring yang sama besar, jumlah mata jaring ke arah horizontal jauh lebih banyak dari pada jumlah mata jaring ke arah vertikal, pada bagian atas dilengkapi beberapa pelampung dan di bagian bawah dilengkapi beberapa pemberat sehingga memungkinkan jaring dapat dipasang di daerah penangkapan dalam keadaan tegak.

Hasil tangkapan menggunakan jaring yaitu ikan wader/bandengan, kating/senggiring, melem, mata merah, barau dan ikan sili.

$\begin{array}{ll}\text { Nama Lokal } & : \text { Jaring } \\ \text { Nama Nasional } & \text { : Jaring Insang } \\ \text { Nama International } & : \text { Gillnets } \\ \text { Jumlah Alat } & : \text { 20 unit }\end{array}$


Daerah Operasi $\quad$ : perairan sungai alai

Tabel 3. Identifikasi Konstruksi Alat Tangkap Jaring

\begin{tabular}{|c|c|c|c|c|c|c|c|}
\hline No & Komponen & $\begin{array}{l}\text { Panjang } \\
(\mathrm{cm})\end{array}$ & $\begin{array}{l}\text { Lebar } \\
(\mathrm{cm})\end{array}$ & $\begin{array}{l}\text { Tinggi } \\
(\mathrm{cm})\end{array}$ & $\begin{array}{l}\text { Mesh } \\
\text { size } \\
(\mathrm{mm})\end{array}$ & $\begin{array}{l}\text { Diameter } \\
/ \varnothing(\mathrm{mm})\end{array}$ & Keterangan \\
\hline 1. & Tali & 2.000 & - & - & - & 65 & - \\
\hline 2 & $\begin{array}{l}\text { Webbing } \\
\text { (badan jaring) }\end{array}$ & 1.500 & - & 90 & 12,7 & - & - \\
\hline 3. & Pemberat & 4,5 & 4,5 & - & - & - & $\begin{array}{c}\text { Genteng / } 13 \\
\text { unit }\end{array}$ \\
\hline
\end{tabular}

Sumber : Data Penelitian 2020.

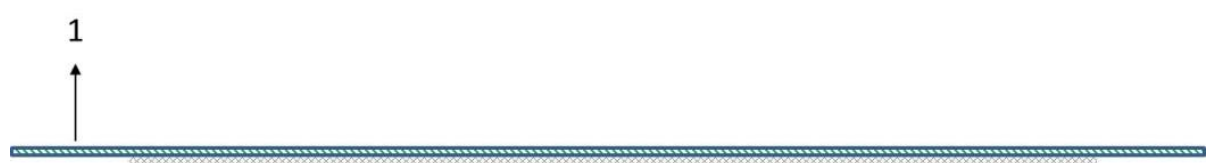

2

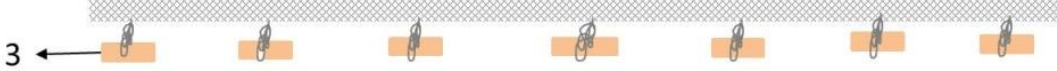

Katerangan :

\section{Tali ris 2. Webbing (Badan Jaring) 3. Pemberat}

Gambar 3. Konstruksi alat tangkap jaring

3. Alat Tangkap Pancing Lempar

Pancing yang digunakan nelayan

di perairan Sungai Alai berjenis katrol atau masyarakat nelayan biasa menyebutnya pancing lempar. Karena kebiasaan masyarakat nelayan mengoperasikan alat tangkap ini dengan cara melempar makanya dinamakan pancing lempar. Pancing lempar terdiri dari joran dengan panjang $180 \mathrm{~cm}$ terbuat dari bahan fiber, kemudian tali berjenis PE dengan panjang 100 meter dan mata pancing yang digunakan yaitu nomer 10 , menurut masyarakat nelayan mata pancing tersebut tidak terlalu besar dan tidak terlalu kecil untuk target tangkapan ikan - ikan sungai seperti ikan gabus. Konstruksi alat tangkap pancing lempar dapat dilihat pada (Gambar 4).

Menurut Kholis et al., (2017), pancing adalah salah satu alat tangkap ikan yang terdiri dari dua komponen utama, yaitu: tali (line) dan mata pancing (hook). Bagian - bagian pancing terdiri atas joran (rod), gulungan (reel), tali pancing (lines), mata pancing (hook). Namun sesuai dengan jenisnya, pancing dapat dilengkapi pula komponen lain seperti: pemberat (sinker), pelampung (float) dan kili - kili (swivel). 
Umpan yang digunakan yaitu menggunakan umpan tipuan. Biasanya masyarakat nelayan membeli umpan tipuan dari toko pancing tetapi ada juga ditemukan masyarakat nelayan yang membuat umpan tipuan sendiri dengan bentuk mirip seperti umpan tipuan yang dijual dipasaran. Hasil tangkapan menggunakan pancing lempar yaitu sejenis ikan gabus/bayong dan toman.

$\begin{array}{ll}\text { Nama Lokal } & \text { : Pancing lempar } \\ \text { Nama Nasional } & \text { : Pancing } \\ \text { Nama International } & : \text { Hook and lines } \\ \text { Jumlah Alat } & : \text { : } 2 \text { unit } \\ \text { Daerah Operasi } & : \text { perairan sungai alai }\end{array}$

Tabel 4. Identifikasi Konstruksi Alat Tangkap Pancing Lempar

\begin{tabular}{llccccc}
\hline No & Komponen & $\begin{array}{l}\text { Panjang } \\
(\mathrm{cm})\end{array}$ & $\begin{array}{l}\text { Lebar } \\
(\mathrm{cm})\end{array}$ & $\begin{array}{l}\text { Tinggi } \\
(\mathrm{cm})\end{array}$ & $\begin{array}{l}\text { No.Mata } \\
\text { pancing }\end{array}$ & $\begin{array}{l}\text { Diameter/Ø } \\
(\mathrm{mm})\end{array}$ \\
\hline 1. & Joran & 180 & - & - & - & - \\
2 & Tali & 10.000 & - & - & - & - \\
3. & Katrol & - & - & - & - & - \\
4. & $\begin{array}{l}\text { Umpan dan mata } \\
\text { pancing }\end{array}$ & - & - & - & 10 & - \\
\hline
\end{tabular}

Sumber : Data Penelitian 2020.

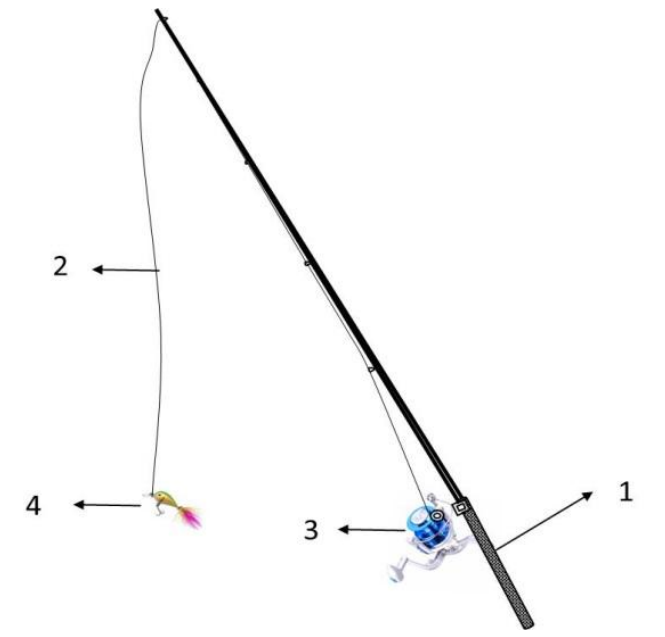

Gambar 4. Konstruksi Alat Tangkap Pancing Lempar
Keterangan:

1. Joran

2. Tali pancing

3. Katrol

4. Umpan dan mata pancing

\section{Alat Tangkap Ambat}

Alat tangkap ambat yang ada di perairan sungai alai merupakan alat tangkap berbentuk jaring mengerucut dangan bagian mulut jaring berukuran lebar dan semakin kebelakang ukurannya semakin kecil serta memiliki kantong dibagian belakang. Konstruksi alat tangkap ambat meliputi panjang keseluruhan $12 \mathrm{~m}$, mulut ambat $2 \mathrm{~m}$, bagian belakang berukuran $30 \mathrm{~cm}$, kawat behel dengan panjang 6 $m$ yang digunakan sebagai cincin dan bahan yang digunakan untuk membuat 
jaring menggunakan benang nilon berjumlah 36 bantal. Lebih jelas dapat dilihat (Gambar 5).

Alat tangkap ambat metode pengoperasiannya yaitu diletakkan ditengah sungai berarus deras dengan pemasangannya menghadap arah aliran sungai. Alat tangkap ini tergolong alat tangkap menetap/pasif yang prinsip kerjanya mengahadang ikan untuk masuk kedalamnya.

Menurut Subani dan Barus (1989), Bubu ambai dapat disebut juga bubu tiang atau perangkap pasang surut berukuran kecil, terbuat dari jaring berbentuk kerucut, pada kanan kiri mulut terdapat gelang-gelang terbuat dari besi atau rotan yang dimasukkan ke dalam tiang-tiang pancang. Bubu ambai diklasifikasikan ke dalam kelompok perangkap dan menghadang.

Hasil tangkapan ikan yang tertangkap menggunakan ambat yaitu: ikan tapah, ikan lais, ikan baung, ikan belida dan ikan barau.

$$
\begin{array}{ll}
\text { Nama Lokal } & : \text { Ambat } \\
\text { Nama Nasional } & \text { : Perangkap } \\
\text { Nama International } & : \text { Traps } \\
\text { Jumlah Alat } & : 1 \text { unit } \\
\text { Daerah Operasi } & \text { : Perairan Sungai Alai }
\end{array}
$$

Tabel 5. Identifikasi Konstruksi Alat Tangkap Ambat

\begin{tabular}{llccccc}
\hline No & Komponen & $\begin{array}{l}\text { Panjang } \\
(\mathrm{cm})\end{array}$ & $\begin{array}{l}\text { Lebar } \\
(\mathrm{cm})\end{array}$ & $\begin{array}{l}\text { Tinggi } \\
(\mathrm{cm})\end{array}$ & $\begin{array}{l}\text { Mesh size } \\
(\mathrm{mm})\end{array}$ & $\begin{array}{l}\text { Jumlah } \\
\text { (bantal) }\end{array}$ \\
\hline 1. & Kayu Pancang & - & - & - & - & - \\
2 & Mulut & - & 200 & - & - & - \\
3 & Badan & 1.200 & - & - & - & - \\
4. & Kantong & - & 30 & - & - & - \\
\hline
\end{tabular}

Sumber : Data Penelitian 2020.

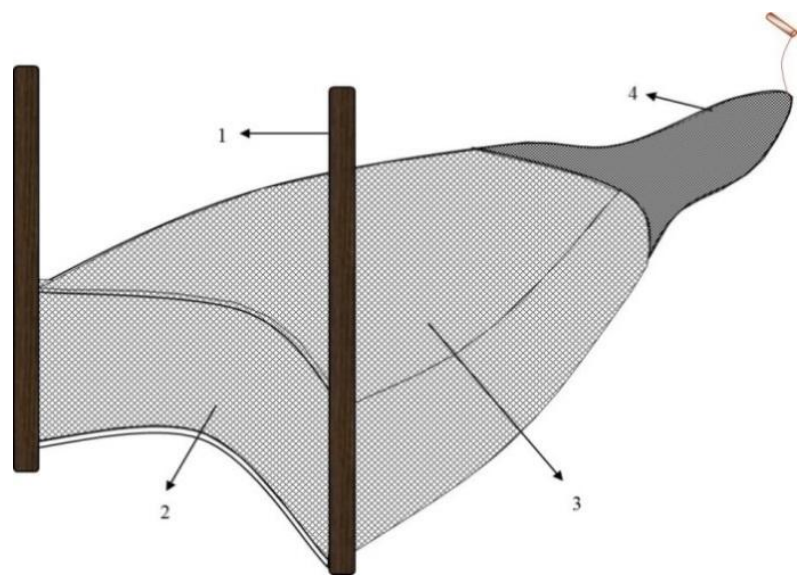

Keterangan:

1. Kayu pancang

2. Mulut

3. Badan

4. Kantong

Gambar 5. Konstruksi alat tangkap ambat 
5. Alat Tangkap Tembak Ikan

Tembak ikan merupakan alat tangkap yang mengharuskan pemakainya untuk menyelam dengan bantuan kaca mata selam ke perairan dalam dengan mecari target tangkapan yakni ikan - ikan besar. Nelayan dituntut mempunyai keahlian dalam berenang karena untuk mecari target tangkapan biasanya membutuhkan waktu yang cukup lama. Konstruksi alat tangkap tembak ikan meliputi besi dengan panjang $80 \mathrm{~cm}$ berdiameter 3 $\mathrm{mm}$, tali dengan panjang $10.000 \mathrm{~cm}$, senapan yang terbuat dari kayu dengan panjang $60 \mathrm{~cm}$, karet ban dalam motor sebanyak 6 helai, mata panah/mata tembak panjang $5 \mathrm{~cm}$ dan memiliki diameter $3 \mathrm{~mm}$. Lebih jelas dapat dilihat pada (Gambar 6).

Alat tangkap ini tergolong alat tangkap penjepit dan melukai karena prinsip kerjanya yaitu mencari target setelah ditemukan lalu membidiknya kemudian menembakkan mata panah atau besi ke bagian tubuh ikan yang sudah menjadi target. Masyarakat nelayan di perairan sungai alai biasanya melakukan operasi penangkapan saat siang hari di bagian sungai yang terdapat tumbuh-tumbuhan seperti pandan. Hasil tangkapan ikan yang biasanya tertangkap menggunakan tembak ikan yaitu: ikan barau, ikan toman, ikan tapah (ukuran 4 jari atau lebih).

$\begin{array}{ll}\text { Nama Lokal } & \text { : Tembak ikan } \\ \text { Nama Nasional } & \text { : Penjepit dan melukai } \\ \text { Nama International } & \text { : Grappling and wounding } \\ \text { Jumlah Alat } & : \text { 1 unit } \\ \text { Daerah Operasi } & \text { : perairan sungai alai }\end{array}$

Tabel 6. Identifikasi Konstruksi Alat Tangkap Tembak Ikan

\begin{tabular}{llccccc}
\hline No & Komponen & $\begin{array}{l}\text { Panjang } \\
(\mathrm{cm})\end{array}$ & $\begin{array}{l}\text { Lebar } \\
(\mathrm{cm})\end{array}$ & $\begin{array}{l}\text { Tinggi } \\
(\mathrm{cm})\end{array}$ & $\begin{array}{l}\text { Diameter/Ø } \\
(\mathrm{mm})\end{array}$ & Jumlah \\
\hline 1. & Besi & 30 & - & - & 3 & 1 \\
2 & Tali & 100 & - & - & 3 & 1 \\
3. & Senapan & 60 & - & - & - & 1 \\
4 & Mata tembak & 5 & - & - & 3 & 1 \\
5. & Karet ban & - & - & - & - & 6 \\
& dalam motor & & - & - & & \\
\hline
\end{tabular}

Sumber : Data Penelitian 2020.

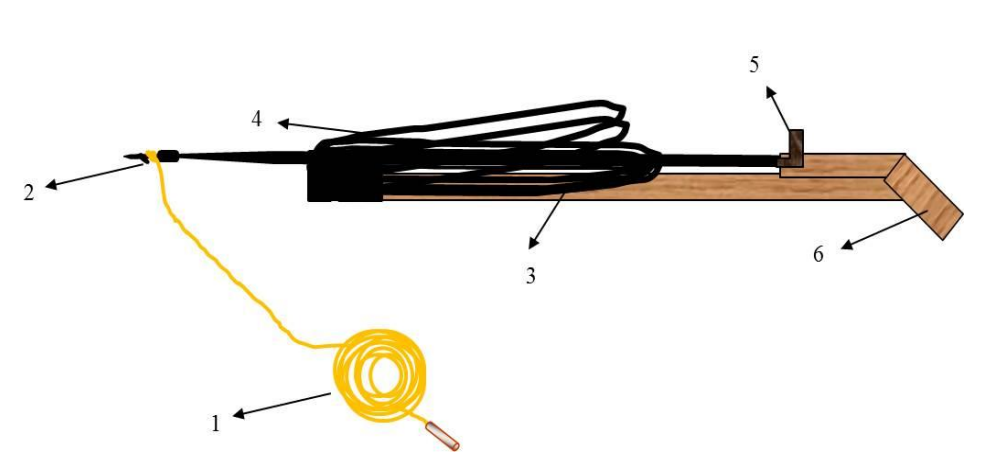

Keterangan :

Gambar 6. Konstruksi Alat Tangkap Tembak Ikan

1. Tali

2. Mata Tembak

3. Karet ban

4. Besi

5. Pelatuk tembak

6. Senapan 
6. Alat Tangkap Pancing Tajur

Pancing tajur atau dalam bahasa masyarakat nelayan di perairan sungai alai alat tangkap ini disebut juga pancing panjer merupakan alat tangkap yang prinsip kerjanya ditancapkan lalu dibiarkan dengan periode waktu tertentu untuk melihat hasil tangkapan. Konstruksi pancing tajur terdiri dari joran/tangkai dengan panjang $2 \mathrm{~m}$, mata pancing No. 10 dibuat 2 cabang dan tali dengan panjang $1 \mathrm{~m}$. Jika dilihat dari bahan pembuatannya alat tangkap ini memang tergolong masih sederhana. Lebih jelas dapat dilihat pada (Gambar 7).

Menurut SNI (8788:2019) pancing merupakan alat tangkap yang bersifat pasif dan memiliki karakteristik menangkap ikan berperilaku soliter atau ikan yang

Nama Lokal : Pancing tajur

Nama Nasional : Pancing

Nama International : Hook and line

Jumlah Alat : :200 unit

Daerah Operasi : Perairan Sungai Alai perilaku hidupnya bergerak sendiri sendiri dengan cara tersangkut atau terkait mata pancing serta pengoperasiannya bisa dilakukan pada permukaan, pertengahan dan dasar perairan. Alat tangkap pancing tajur dalam PERMEN KP No. 02 Tahun 2011 termasuk dalam alat tangkap pancing (hook and lines). Umpan yang digunakan yaitu ikan - ikan kecil yang masih hidup. Daerah penangkapan pancing tajur biasanya di bagian pinggir sungai pada kedalaman $\pm 1 \mathrm{~m}$ dengan kondisi perairan sedikit berarus.

Hasil tangkapan ikan yang biasanya tertangkap menggunakan pancing tajur yaitu: ikan baung, ikan lais, ikan tapah, ikan toman, ikan barau.

Tabel 7. Identifikasi Konstruksi Alat Tangkap Pancing Tajur

\begin{tabular}{llccccc} 
No & Komponen & $\begin{array}{l}\text { Panjang } \\
(\mathrm{cm})\end{array}$ & $\begin{array}{l}\text { Lebar } \\
(\mathrm{cm})\end{array}$ & $\begin{array}{l}\text { Tinggi } \\
(\mathrm{cm})\end{array}$ & $\begin{array}{l}\text { Diameter/Ø } \\
(\mathrm{mm})\end{array}$ & No. Mata pancing \\
\hline 1. & Joran/tangkai & 200 & - & - & - & - \\
2 & Tali & 100 & - & - & - & - \\
3. & Mata pancing & - & - & - & - & 5 dan 10 \\
\hline
\end{tabular}

Sumber : Data penelitian 2020.

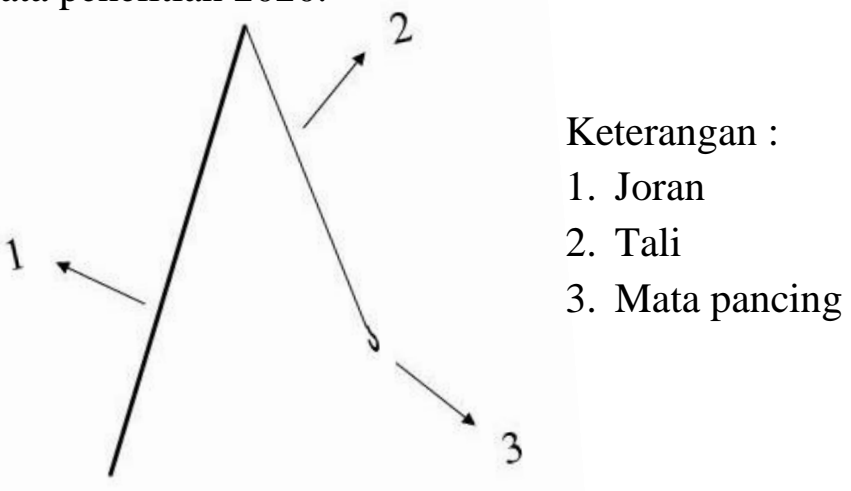

Gambar 3. Konstruksi Alat Tangkap Pancing Tajur 
7. Alat Tangkap Rawai

Alat tangkap rawai merupakan jenis alat tangkap pancing yang tidak menggunakan bantuan joran pada saat pengoperasian. Alat tangkap ini terdiri dari tali panjang sebagai komponen utamanya dan dibuat tali cabang untuk memasang mata pancing. Konstruksi rawai yaitu tali dengan panjang $10 \mathrm{~m}$, mata pancing no.7 dengan jarak pemasangan antar tali cabang $2 \mathrm{~m}$ dan rotan dengan panjang $20 \mathrm{~cm}$ yang diikatkan pada tali cabang agar tali cabang tidak mudah hanyut terbawa arus. Lebih jelas lihat pada (Gambar 8).

Menurut Wijayanti et al., (2015) Alat tangkap rawai adalah salah satu alat tangkap yang termasuk di dalam klasifikasi longline yang secara harfiah dapat diartikan dengan tali panjang. Rawai merupakan salah satu alat tangkap yang bersifat pasif. Pada pengoperasiannya rawai memperlukan umpan untuk menarik ikan. Umpan di letakkan atau di kaitkan pada mata pancing. Kegunaan dari mata pancing itu sendiri yaitu untuk memastikan agar ikan tidak dapat melepaskan diri setelah terkait pada mata pancing.

Masyarakat nelayan di perairan sungai alai biasanya melakukan penangkapan di pinggir atau tengah sungai dengan kondisi perairan sedikit berarus, menggunakan umpan ikan ikan kecil yang masih hidup tujunnya untuk menarik ikan - ikan besar sebagai target tangkapan. Pemasangan dilakukan pada periode waktu tertentu sebelum melihat hasil tangkapannya.

Hasil tangkapan ikan yang tertangkap menggunakan rawai yaitu: ikan baung, ikan tapah, ikan betutu.

$$
\begin{array}{ll}
\text { Nama Lokal } & \text { : Rawai } \\
\text { Nama Nasional } & \text { : Pancing } \\
\text { Nama International } & : \text { Hook and line } \\
\text { Jumlah Alat } & : \text { unit } \\
\text { Daerah Operasi } & \text { : perairan sungai alai }
\end{array}
$$

Tabel 8. Identifikasi Konstruksi Alat Tangkap Rawai

\begin{tabular}{llccccc} 
No & Komponen & $\begin{array}{l}\text { Panjang } \\
(\mathrm{cm})\end{array}$ & $\begin{array}{l}\text { Lebar } \\
(\mathrm{cm})\end{array}$ & $\begin{array}{l}\text { Tinggi } \\
(\mathrm{cm})\end{array}$ & $\begin{array}{l}\text { Diameter/Ø } \\
(\mathrm{mm})\end{array}$ & No. Mata pancing \\
\hline 1. & Tali utama & 1.000 & - & - & - & - \\
2. & Mata pancing & - & - & - & - & 7 \\
3. & $\begin{array}{l}\text { Tali cabang } \\
\text { mata pancing }\end{array}$ & 10 & - & - & - & - \\
4. & Rotan & 20 & - & - & - & - \\
5. & Kayu Pancang & - & - & - & - & - \\
\hline
\end{tabular}

Sumber : Data penelitian 2020. 


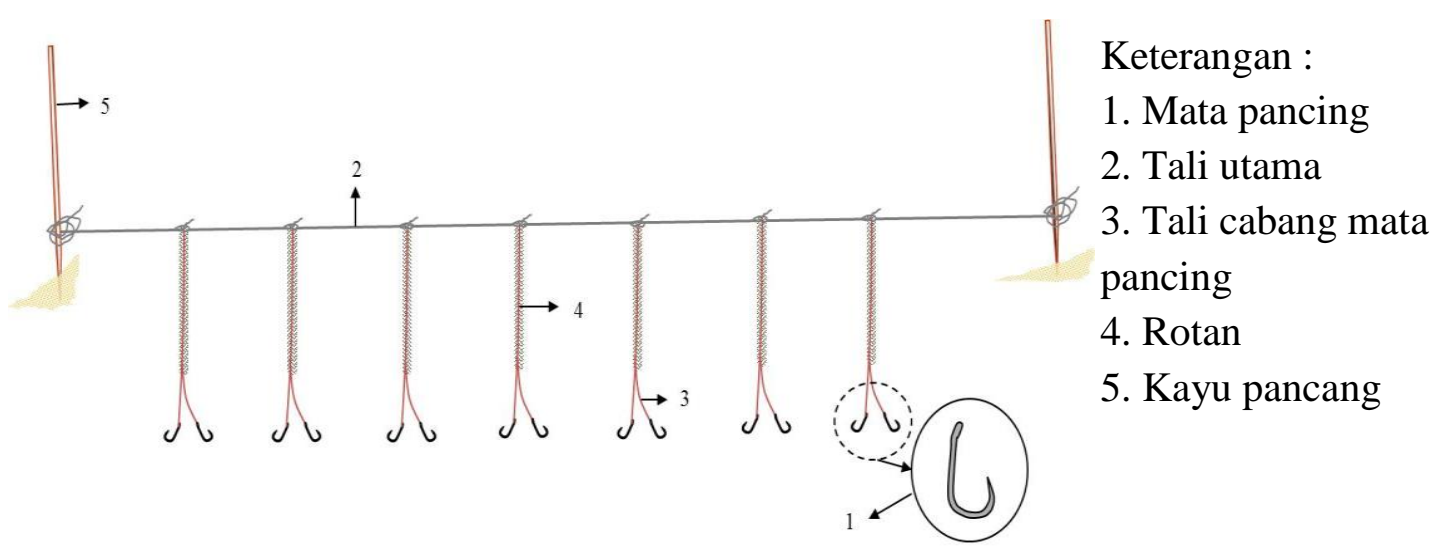

Gambar 8. Konstruksi Alat Tangkap Rawai

\section{Alat Tangkap Bubu Kawat}

Bubu kawat mempunyai cara kerja yang sama seperti bubu pada umumnya yaitu mempermudah masuk dan mempersulit keluarnya. Untuk mempermudah memerangkap ikan digunakanlah umpan sebagai penariknya agar masuk kedalam bubu dan tidak bisa keluar lagi. Alat tangkap ini terbuat dari kawat makanya masyarakat nelayan di perairan sungai alai menyebutnya bubu kawat. Konstruksi utama yang digunakan dalam pembuatan bubu kawat yaitu panjang bubu $80 \mathrm{~cm}$, mulut bubu berdiameter $50 \mathrm{~cm}$, kawat mesh atau jaring pagar kandang dengan diameter 0,5 inci, injab dengan diameter $25 \mathrm{~cm}$, lingkaran untuk bagian pembentuk rangka menggunakan rotan ,tali untuk memasang dan mengangkat bubu. Lebih jelas dapat dilihat pada (Gambar 9). (2019)

Reppie (1989); Chaliluddin et al., menyatakan bahwa penangkapan menggunakan bubu mempunyai kelebihan dalam pengelolaan jika dibandingkan dengan usaha perikanan lainnya, dimana hasil tangkapan pada umunya diperoleh masih dalam keadaan hidup, sehingga disamping dapat terjamin kesegaran yang tinggi, juga mudah dalam pengelolaan sumberdaya perikanan; seperti melepaskan hasil tangkapan kembali jika ukurannya belum layak ditangkap (legal size).

Lokasi yang menjadi daerah penangkapan atau pemasangan bubu kawat yaitu di pinggir sungai pada kedalaman \pm 2 meter dengan kondisi perairan sedikit berarus. Masyarakat Nelayan di Perairan Sungai Alai biasa menggunakan umpan berupa buah kelapa sawit.

Hasil tangkapan ikan yang biasanya tertangkap menggunakan bubu kawat yaitu: ikan hijau, ikan beterung, ikan gresik, ikan lang, ikan lais.

$\begin{array}{ll}\text { Nama Lokal } & \text { : Bubu kawat } \\ \text { Nama Nasional } & \text { : Perangkap } \\ \text { Nama International } & : \text { Traps } \\ \text { Jumlah Alat } & : 9 \text { unit } \\ \text { Daerah Operasi } & \text { : perairan sungai alai }\end{array}$


Tabel 9. Identifikasi Konstruksi Alat Bubu Kawat

\begin{tabular}{llccccc}
\hline No & Komponen & $\begin{array}{l}\text { Panjang } \\
(\mathrm{cm})\end{array}$ & $\begin{array}{l}\text { Lebar } \\
(\mathrm{cm})\end{array}$ & $\begin{array}{l}\text { Tinggi } \\
(\mathrm{cm})\end{array}$ & $\begin{array}{l}\text { Diameter/Ø } \\
(\mathrm{mm})\end{array}$ & $\begin{array}{c}\text { Mesh size } \\
(\mathrm{mm})\end{array}$ \\
\hline 1. & Injab & - & - & - & 250 & - \\
2. & Badan & 80 & - & - & - & - \\
3. & Kawat mesh & - & - & - & - & 0,5 \\
4 & Rotan & - & - & - & - & - \\
5. & Tali & - & - & - & - & - \\
6. & Mulut bubu & - & - & - & 500 & - \\
\hline
\end{tabular}

Sumber : Data Penelitian 2020.

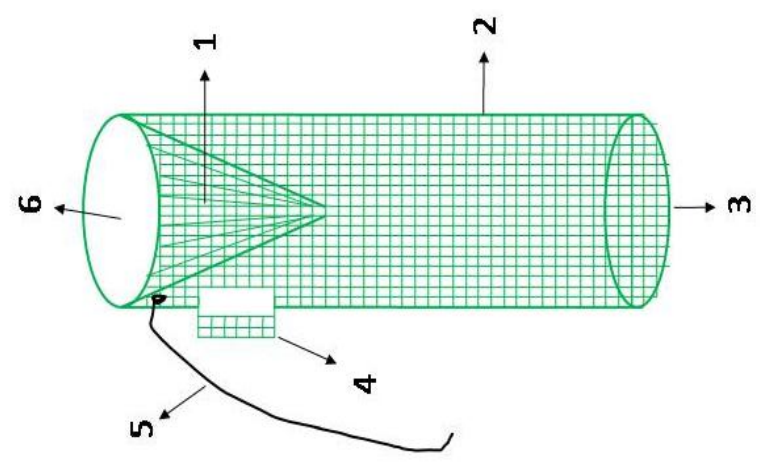

Keterangan :

1. Injab

2. Badan bubu (kawat mesh)

3. Rotan

4. Pintu pengambilan hasil tangkapan

5. Tali

6. Mulut bubu

Gambar 9. Konstruksi Alat Tangkap Bubu Kawat

Tingkat Keramah Lingkungan Alat Tangkap yang Teridentifikasi

Hasil penelitian menunjukkan bahwa alat tangkap yang teridentifikasi di perairan sungai alai Kabupaten Tebo berjumlah 8 jenis yaitu sruwo (bubu galon), jaring, pancing lempar, ambai, tembak ikan, pancing tajur, rawai dan bubu kawat.

Tingkat keramah lingkungan alat penangkapan sruwo memperoleh skor 34 maka alat tangkap sruwo tergolong dalam alat tangkap sangat ramah lingkungan. Kemudian alat penangkapan jaring memperoleh skor 35 yang berarti termasuk alat tangkap sangat ramah lingkungan, alat tangkap pancing lempar memperoleh skor 36 maka alat tangkap pancing lempar tergolong dalam alat tangkap sangat ramah lingkungan, alat tangkap ambat memiliki skor 33 dengan kriteria alat penangkapan sangat ramah lingkungan, alat tangkap tembak ikan mendapatkan skor 34 yang berarti alat tangkap ini berkriteria sangat ramah lingkungan, untuk alat tangkap pancing tajur memperoleh skor 35 ini artinya alat penangkapan berkriteria sangat ramah lingkungan, untuk alat tangkap rawai dan alat tangkap bubu kawat masing masing mendapat skor 36 dan 35 yang 
berarti termasuk juga alat tangkap ramah lingkungan.

Dilihat dari 8 jenis alat tangkap yang teridentifikasi semuanya termasuk kategori sangat ramah lingkungan, hal itu dapat dilihat dari konstruksi alat tangkap yang sederhana dan masih tradisional. Lebih jelas dapat dilihat pada (Gambar 10).
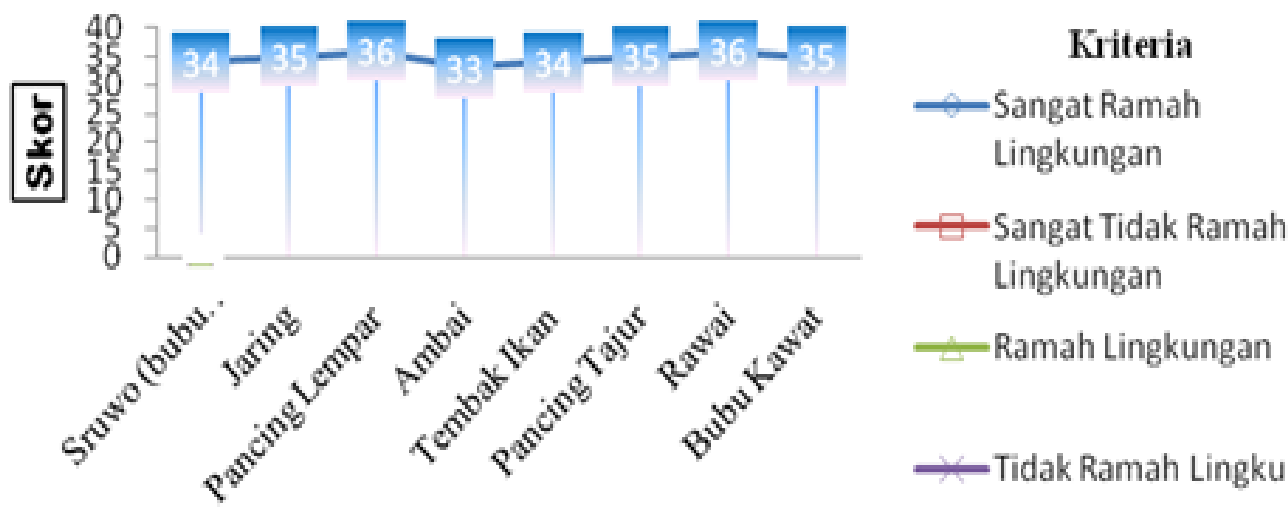

$\leftarrow$ Ramah Lingkungan

CTidak Ramah Lingkungan

\section{Jenis Alat Tangkap}

Gambar 10. Hasil Analisis Keramahan Lingkungan Alat Tangkap Di Perairan Sungai Alai Kabupaten Tebo

Hasil penelitian Subehi et al., (2017) alat tangkap yang termasuk sangat ramah lingkungan yaitu rawai, gill net (Sumardi et al., 2014; Kholis et al., 2018; Anggraini et al., 2019), pancing Anggraini et al., 2019) dan dogol. Selain itu ditambahakan Nanlohy, (2013); Tuasikal (2020) alat tangkap sangat ramah lingkungan juga ada pancing tonda, huhate, drift surface gillnet, bagan, pancing tegak, jaring insang dasar, jaring bobo/pukat cincin, dan payang. Alat tangkap yang termasuk ramah lingkungan yaitu bubu dan jaring insang permukaan (Latuconsina, 2010) trammel net dan

\section{KESIMPULAN DAN SARAN}

Berdasarkan hasil penelitian yang telah dilakukan, dapat disimpulkan bahwa: Alat penangkapan ikan di Perairan Sungai Alai yang melewati Kecamatan Rimbo Ulu, Rimbo Bujang, Rimbo Ilir dan Tebo Tengah teridentifikasi 8 jenis alat tangkap, purse seine (Sumardi et al., 2014) serta bagan (Anggraini et al., 2019). Alat tangkap tidak ramah lingkungan menurut Latuconsina (2010) seperti: jala dan jaring dasar. Sedangkan alat tangkap yang termasuk tidak ramah lingkungan menurut Latuconsina (2010) yaitu: bom, bius dan bameti. Sedangkan menurut Yuda et al., (2012) yang sangat tidak ramah lingkungan berdasarkan hasil tangkapan utama, length at first maturity dan by catch yaitu bagan. Selain itu ada pukat pantai (Nanlohy, 2013), arad (Subehi et al., 2017), dan alahan/bubu (Anggraini et al., 2019),

\section{Kesimpulan}

yaitu terdiri dari: sruwo (bubu galon), jaring, pancing lempar, ambat, tembak ikan, pancing tajur, rawai dan bubu kawat. Dari 8 jenis alat penangkapan yang teridentifikasi, semuanya berkategori sangat ramah lingkungan. 


\section{Saran}

Diharapkan kepada masyarakat nelayan di perairan sungai alai Kabupaten Tebo agar tetap mempertahankan penggunaan alat

\section{DAFTAR PUSTAKA}

Anggraini A., Rengi P., Usman (2019). Identifikasi Alat Tangkap Ramah Lingkungan Yang Dioperasikan di Perairan Danau Singkarak Provinsi Sumatera Barat. JOM, 1(1):1-13.

Badan Pusat Statistik. (2018). Provinsi Jambi Dalam Angka. Badan Pusat Statistik Provinsi Jambi. [diunduh 14 Juni 2020]. Dapat diakses di:

https://jambi.bps.go.id/publicatio $\mathrm{n} / 2018 / 08 / 16 / 463 \mathrm{fb} 7693 \mathrm{f} 6 \mathrm{a} 2178$

2bbe309c/provinsi-jambidalamangka-2018.html.

Chaliluddin, M. A., Ikram, M., \& Rianjuanda, D. (2019). Identifikasi Alat Penangkapan Ikan Ramah Lingkungan Berbasis CCRF di Kabupaten Pidie, Aceh. Jurnal Galung Tropika, 8(3), 197-208.

Dahuri, R. (2000). Pembangunan Kawasan Pesisir dan Lautan. Jurnal Ekonomi Lingkungan. Bandung. Journal of Fisheries Resources Utilization Management and Technology Volume 7, Nomor 2, Tahun 2018, Hlm 89-95.

Dirjen Perikanan Tangkap. 2005. Petunjuk Teknis Penangkapan Ikan Ramah Lingkungan. Departemen Kelautan dan Perikanan. Jakarta. Jurnal Ilmiah agribisnis dan Perikanan (agrikan UMMU-Ternate) Volume 3 Edisi 2 (Oktober 2010). tangkap yang ramah lingkungan yang tidak berbahaya dan merusak lingkungan sehingga kelestarian sumberdaya Perairan Sungai Alai tetap terjaga.

Food Agriculture Organization (FAO). 1995. Code of Conduct for Responsible Fisheries (CCRF). FAO Fisheries Departement Jurnal analisis alat penangkap ikan berbasis code of conduct for responsible fisheries (CCRF) di tempat pelelangan ikan tawang, kendal, saintek perikanan Vol.13 No.1:65-74, agustus 2017.

Irpan, A., Djunaidi, D., \& Hertati, R. (2018). Pengaruh Ukuran Mata Jaring (Mesh Size) Alat Tangkap Jaring Insang (Gill Net) Terhadap Hasil Tangkapan di Sungai Lirik Kecamatan Jangkat Timur Kabupaten Merangin Provinsi Jambi. SEMAH Jurnal Pengelolaan Sumberdaya Perairan, 2(2).

Kholis, M. N., Jaya, M. M., Hutapea, R. Y., Bangun, T. N. C., \& Hehanussa, K. G. (2018). Karakteristik Alat Tangkap Jaring Insang (Gill Net) di Pangkalan Pendaratan Ikan (PPI) Muara Angke Jakarta Utara. SEMAH Jurnal Pengelolaan Sumberdaya Perairan, 2(2).

Kholis, M. N., Wahju, R. I., \& Mustaruddin, M. (2017). Keragaan Aspek Teknis Unit Teknologi Penangkapan Ikan Kurau di Pambang Pesisir Kabupaten Bengkalis Provinsi Riau. Jurnal Teknologi Perikanan dan Kelautan, 8(1), 67-79. 
Kurohman, F., Chairunnisa, S., \& Bambang, A. N. Studi Kasus Penangkapan Ikan Yang Ramah Lingkungan Di Pangkalan Pendaratan Ikan (PPI) Celong, Kabupaten Batang (Case Study of Eco-Friendly Fishing Gears at Celong Fishing Port, Batang Regency). Saintek Perikanan: Indonesian Journal of Fisheries Science and Technology, 14(1), 63-69.

Latuconsina, H. (2010). Identifikasi alat penangkapan ikan ramah lingkungan di kawasan konservasi laut Pulau Pombo Provinsi Maluku. Agrikan: Jurnal Agribisnis

Perikanan, 3(2), 23-30.

Lisna.,Jasmine Masyitha Amelia., Nelwida Dan Mia Andriani.2018. Tingkat Keramah Lingkungan Alat Tangkap Gill Net DiKecamatan Nipah Panjang, Program Studi Pemanfaatan Sumberdaya Perikanan, Fakultas Peternakan, Universitas Jambi. Jambi. Jurnal Teknologi Perikanan Dan Kelautan Vol. 9 No. 1 Mei 2018: 83-96.

Martasuganda, S. (2002). Jaring Insang (Gill net) Serial Teknologi Penangkapan Ikan Berwawasan Lingkungan. Jurusan

Pemanfaatan Sumberdaya Perikanan, Fakultas Ilmu Perikanan Dan Kelautan, Institut Pertanian Bogor, Bogor, 68.

Monintja, D. 2001. Pemanfaatan Sumberdaya Pesisir Dalam Bidang Perikanan Tangkap. Prosiding Pelatihan Pengelolaan Wilayah Pesisir Terpadu.Pusat Kajian Sumberdaya Pesisir dan
Laut. Institut Pertanian Bogor. Bogor. Jurnal Alat Penangkapan Ikan Yang Ramah Lingkungan Berbasis Codeof Conduct ForResponsible Fisheries di Kota Banda Aceh. Agrisep Vol (15) No. 2 , 2014.

Nanlohy, A. C. (2013). Evaluasi alat tangkap ikan pelagis yang ramah lingkungan di Perairan Maluku dengan menggunakan prinsip CCRF (Code of Conduct for Responsible Fisheries). Jurnal Ilmu Hewani Tropika (Journal Of Tropical Animal Science),2(1), 1-11.

Nawawi H. Hadari. 1998. Metode Penelitian Bidang Sosial. Yogyakarta: Gadjah Mada University Press.

Reppie, E. (1989). A mathematical study on catching mechanisms of pot fishery (Doctoral dissertation, Master Thesis. Laboratory of Fisheries Resources Management).

Sima, A. M. (2014). Identifikasi Alat Tangkap Ikan Ramah Lingkungan di Desa Bagan Asahan Kecamatan Tanjung Balai.

Subani, W., \& Barus, H. R. (1988). Alat Penangkapan Ikan dan Udang Laut di Indonesia Jumal Penelitian Perikanan Laut Nomor 50 Tahun 1988/1989. Jakarta (ID): Balai Penelitian Perikanan Badan Penelitian dan Pengembangan Pertanian Departemen Pertanian, 248.

Subehi, S., Boesono, H., \& Dewi, D. A. N. N. (2017). Analisis alat penangkap ikan ramah lingkungan berbasis code of 
conduct for responsible fisheries

(CCRF) di TPI Kedung Malang

Jepara. Journal of Fisheries

Resources Utilization

Management and Technology,

6(4), 01-20.

Sugiyono.2014. Metode Penelitian

Pendidikan (Pendekatan

Kuantitatif, Kualitatif dan R\&D).

Alfabeta. Bandung. Jurnal

Tingkat Keramah Lingkungan

Alat Tangkap Gill Net Di

Kecamatan Nipah Panjang,

JambiTeknologi Perikanan Dan

Kelautan. Vol. 9 No. 1 Mei 2018:

83-96.

Sumardi, Z., Sarong, M. A., \& Nasir,

M. 2014. Alat penangkapan ikan

yang ramah lingkungan berbasis code of conduct for responsible fisheries di Kota Banda Aceh. Universitas Syiah Kuala. Banda Aceh. Jurnal Agrisep, Vol (15) No.2, 2014.

Tuasikal, T. (2020). Inventarisasi Alat Tangkap Ramah Lingkungan di Desa Werinama. Agrohut, 10(1), 19-24.

Wijayanti, A. C. W., Boesono, H., \& Bambang, A. N. (2015). Analisis Ekonomi Rawai Dasar dengan J Hook dan Circle Hook di PPI Ujungbatu Jepara Jawa Tengah. Journal of Fisheries Resources Utilization

Management and Technology, 4(4), 179-187.

Yuda, L. K., \& Khan, A. M. (2012). Tingkat keramahan lingkungan alat tangkap bagan di perairan Palabuhanratu, Kabupaten Sukabumi. Jurnal Perikanan Kelautan, 3(3). 